\title{
THE POLITICAL ECONOMY OF PUBLIC INCOME VOLATILITY: WITH AN APPLICATION TO THE RESOURCE CURSE
}

\author{
James A. Robinson \\ Ragnar Torvik \\ Thierry Verdier \\ Working Paper 21205 \\ http://www.nber.org/papers/w21205 \\ NATIONAL BUREAU OF ECONOMIC RESEARCH \\ 1050 Massachusetts Avenue \\ Cambridge, MA 02138 \\ May 2015
}

The views expressed herein are those of the authors and do not necessarily reflect the views of the National Bureau of Economic Research.

NBER working papers are circulated for discussion and comment purposes. They have not been peerreviewed or been subject to the review by the NBER Board of Directors that accompanies official NBER publications.

(C) 2015 by James A. Robinson, Ragnar Torvik, and Thierry Verdier. All rights reserved. Short sections of text, not to exceed two paragraphs, may be quoted without explicit permission provided that full credit, including $(\mathbb{C}$ notice, is given to the source. 
The Political Economy of Public Income Volatility: With an Application to the Resource Curse James A. Robinson, Ragnar Torvik, and Thierry Verdier

NBER Working Paper No. 21205

May 2015

JEL No. D72,D78,Q2

\begin{abstract}
$\underline{\text { ABSTRACT }}$
We develop a model of the political consequences of public income volatility. As is standard, political incentives create inefficient policies, but we show that making income uncertain creates specific new effects. Future volatility reduces the benefit of being in power, making policy more efficient. Yet at the same time it also reduces the re-election probability of an incumbent and since some of the policy inefficiencies are concentrated in the future, this makes inefficient policy less costly. We show how this model can help think about the connection between volatility and economic growth and in the case where volatility comes from volatile natural resource prices, a characteristic of many developing countries, we show that volatility in itself is a source of inefficient resource extraction.
\end{abstract}

\author{
James A. Robinson \\ Harvard University \\ Department of Government \\ N309, 1737 Cambridge Street \\ Cambridge, MA 02138 \\ and NBER \\ jrobinson@gov.harvard.edu \\ Ragnar Torvik \\ Norwegian University of Science and Technology \\ Department of Economics \\ N-7491 Trondheim \\ Norway \\ ragnar.torvik@svt.ntnu.no
}

Thierry Verdier

PSE and ENPC

48 Boulevard Jourdan

75014 Paris France

and CEPR

verdier@pse.ens.fr 


\section{Introduction}

The literature on the political economy of public policy has discovered many mechanisms through which the equilibrium policy chosen through a political process deviates from that which is socially desirable. This is true even in simple models where the median voter theorem applies when median and mean income differ (Romer, 1975, Roberts, 1977). In models where elections are modelled more explicitly many types of inefficiencies stem from the fact that incumbent politicians have an incentive to move policy away from what is socially desirable either because the probability of losing power makes them discount the future too much (Alesina and Tabellini, 1990a,b, Leblanc, Snyder, and Tripathi, 1990), or because this allows them to manipulate their re-election probability in a favorable way (Aghion and Bolton, 1990, Besley and Coate, 1998, Biais and Perotti, 2002, Robinson and Torvik, 2005, Robinson and Verdier, 2013).

These models tend to have simple and appealing comparative statics. For example, anything which increases the benefits of being in power or holding office tends to make policy less efficient. Anything which makes the election outcome less sensitive to policy, such as changes in the distribution of shocks in a probabilistic voting model, tends to make policy more efficient.

In this paper we develop a model of what to our knowledge is a new type of comparative static in a canonical political economy model of inefficient policy. For standard reasons policy is set inefficiently because this helps to raise the re-election probability of an incumbent. In the specific set-up we use, society is divided into two groups one associated with an incumbent, one with an opponent. The two groups value different sorts of public goods which gives the members of a particular groups a desire to elect their politician since only then will they benefit from the public goods that he and they value. In addition the incumbent uses patronage employment, which is socially inefficient, to induce voters to support him.

The main innovation is to embed this model into an environment where government revenues are stochastic and future revenues, after re-election, are uncertain. We show that this has interesting implications for both the re-election probability and the efficiency of policy. More specifically, uncertainly about future government income has important consequences for the efficiency of policy. This works through two main channels. On the one hand uncertainly about future government income tends to reduce the expected benefit of being in power to an incumbent which makes policy more efficient. On the other hand, when revenues and future public good provision are uncertain, the continuation expected utility that members of an incumbents group get from him being re-elected is lower and this reduces his re-election probability. When the re-election probability is lower, this makes inefficient policy less costly, since some of the costs are concentrated in the future, thus encouraging it. We show that this latter effect dominates when the incumbent politician is from the group which values public goods highest and when preferences for public goods are sufficiently heterogeneous between groups or if public sector 
wages are not too high compared to private sector productivity. When this is true higher volatility of government revenues reduces national income.

We then extend this model by including a public sector investment in the initial period which can raise private sector productivity in the second period. Though this may be desirable from a social point of view it has an immediate unappealing political effect for the incumbent: by driving up private sector productivity it reduces the gap between public sector wages and returns in the private sector which makes patronage employment less effective as a tool for influencing election results. However, we also allow it to have a positive effect since we introduce taxation of the private sector and since politicians benefit from tax revenues this tends to stimulate investment. We show that in the plausible case where the return to holding power is large, patronage employment and public investment are strategic substitutes so when income volatility increases patronage employment, it simultaneously tends to decrease public investment. This makes the policy equilibrium even less efficient and induces more channels via which revenues volatility can reduce national income.

This model therefore produces a new mechanism which can help explain some important stylized facts. In particular, Ramey and Ramey (1995) first documented that there is a strong negative correlation between the volatility of output and the rate of economic growth and this seems well established empirically (see Aghion and Banerjee, 2005, Loayza, Rancière, Servén, and Ventura, 2007, for overviews of this very large literature). Existing explanations emphasize the link between volatility and credit constraints (Aghion and Banerjee, 2005, Aghion, Angeletos, Banerjee and Manova, 2010). Our model suggests another channel via which volatility may influence economic growth. Most of the existing evidence looks at the volatility of GDP and in our model anything which generates income volatility, such as shocks to total factor productivity or mechanisms that work through aggregate demand, would convert into shocks to the government budget via their impact on tax revenues. In our model higher volatility creates lower GDP per-capita by inducing more wasteful patronage and lower public investment according to the mechanisms we described above.

But what generates this volatility of government revenues? Where does it come from? Koren and Tenreyrom (2007) show that output volatility is higher in poor countries (see also Acemoglu and Zilibotti, 1997) and in many such poor and developing countries most government revenues come from natural resource rents and natural resources have notoriously volatile prices. Bleaney and Halland (2010) find that a high share of resources in exports is associated with high economic and fiscal volatility and low growth. Hence a plausible source of uncertainly in government revenues come from uncertainly about resource prices. As van der Ploeg (2011) points out, resource revenues are much more volatile than GDP and he suggests several mechanisms via which the volatility of resource prices could translate into poor economic performance. For example, van der Ploeg and Poelhekke (2009) argue that commodity price volatility makes 
liquidity constraints more likely to bind and thus reduce innovation and growth. They present evidence that the adverse growth effect of natural resources results mainly from volatility of commodity prices, though there are important heterogeneous effects (the impact of volatility is higher for point-based resources (oil, diamonds); in landlocked, ethnically polarized economies with weak financial institutions; where there are current account restrictions and when there is high capital account mobility) (see also van der Ploeg and Poelhekke, 2010). Leong and Mohaddes (2011) also find robust evidence that it is the volatility, rather than the level of natural resource rents which is negatively associated with economic growth.

With these interesting empirical connections in mind we then extend our model to take into account that government revenues may be generated from natural resource rents the price of which are subject to uncertainly. This is particularly interesting since the revenues generated by resources in the future depends not just on the stochastic nature of the resource price, but also on the endogenously derived extraction path. We first show that even when there is no patronage employment, the path of natural resource extraction determined in a political equilibrium tends to deviate from the socially efficient (utilitarian) path. Part of the reasons for this have nothing to do with uncertainty and only with the simple fact that once an incumbent choosing resource extraction today may not be re-elected in the future, he tends to over-extract resources relative to the efficient path (Robinson, Torvik and Verdier, 2006, 2014). More interestingly, when resource extraction is chosen by a politician, rather than a benevolent social planner, the politician only provides the type of public goods that he and his group value. This implies that future uncertainty about the resource price creates greater volatility in public good provision (since the politician does not smooth public good provision across groups like the social planner would) and this volatility encourages greater extraction in the present. This mechanism leads to even more resource extraction than would be socially desirable. van der Ploeg (2010) characterized the socially efficient extraction path under uncertainty, showing that resource extraction in the present should be higher than when the price is deterministic. We show, therefore, that natural political economy considerations lead uncertainty to increase resource extraction by even more than what is socially efficient.

The rest of the paper is organized as follows. In Section 2 we set up a basic first political economy model of public income volatility. In Section 3 we apply and extend our framework to study resource price volatility, resource extraction, and the political economy of the resource curse. In Section 4 we conclude.

\section{A simple political economy model of public income volatility}

We consider a society populated by a continuum of voters, with measure normalized to 1 . Each voter belongs to one of two groups, and each group $A, B$ is of equal size $\frac{1}{2}$. There is one politician 
from each group, and the politician from group $A$ initially holds power. With a slight abuse of notation we use the supscript $i$ to denote a voter, a politician, as well as the group the voter or politician belongs to. A voter $i$ in group $i \in\{A, B\}$ have preferences over a private good $C_{t}^{i}$ and a group-specific public good $G_{t}^{i}$ at each point in time $t \in\{1,2\}$, with the following per period utility function:

$$
U_{t}^{i}=C_{t}^{i}-\gamma^{i} \frac{\left(\bar{G}-G_{t}^{i}\right)^{2}}{2} \text { for } i \in\{A, B\},
$$

with $\bar{G}>0$ and $t \in\{1,2\}$ denoting the time period. There is no discounting, so total utility is simply the sum of the per period utilities. This quadratic (concave) specification of the public good utility introduces a need for public policy smoothing. $\gamma^{i}$ is higher the more important is public goods for utility relative to private goods consumption, and we allow it to differ between groups. Some groups may put a higher value on, or be in higher need of, public goods provision than others. Unlike previous literature, we investigate how public sector income volatility affects political incentives, and equilibrium policy, in such a setting. ${ }^{1}$

In period $t \in\{1,2\}$ there is public sector income $Z_{t}$. Future public sector income is uncertain. We thus assume that $Z_{2}$ is stochastic, and such that $Z_{2}=\overline{Z_{2}}+\epsilon$ with $\overline{Z_{2}}>0$ and $\epsilon$ a random variable defined on $[-a, a]$ such that $E(\epsilon)=0$ and $\operatorname{var}(\epsilon)=\sigma^{2}{ }^{2}$

In the first period, the incumbent politician has to decide on how to allocate public sector income between his own consumption, public goods, and patronage transfers to individual citizens (through the number of public offices $L_{t}^{i}$ at a fixed public wage $W>H$ where $H$ is the productivity of the private sector). Patronage is not socially optimal, and to capture this in a simple way we set the productivity in these types of public jobs to zero. At the end of the first period there is an election. We assume that the election may be affected by patronage. One simple way to do this is to assume that a politician in power in the future will not fire public workers from his own group, but will fire public workers from the other group. Then the future utility of patronage workers is linked to the political success of their patron. ${ }^{3}$

In the second period, after the election, whichever politician wins takes power. That politician first decides how much to take away for his own consumption. Then there is the realization

\footnotetext{
${ }^{1}$ van der Ploeg (2010) uses a similar specification for the public good utility to analyze the question of optimal resource extraction. We will return to a comparison between his socially optimal extraction path and the political equilibrium extraction path when we apply and extend our appoach to deal with resource extraction in Section 3.

${ }^{2}$ We extend the model to include taxes in Section 2.6.

${ }^{3}$ There is is an extensive literature discussing how and why patronage may be credible, and may therefore affect elections. A common element in the part of the literature where voting cannot be observed is that, in one way or another, a politician can more credibly commit not to fire public sector workers from his own group than from the other group. There may be many different reasons for patronage to groups close to the politician to be more credible than patronage to groups distant from the politician. These may incude preferences for own group members, efficiency wages, higher costs of firing own group vorkers, the politician resting his leadership on internal support in his own group, easier monitoring of how own group members vote, etc. For different microfoundations see e.g. Robinson and Torvik (2005), Robinson, Torvik and Verdier (2006), Robinson and Verdier (2013). The paticular microfoundaton chosen is not essential for our analysis, and thus we use our reduced form assumption to simplify the analysis.
} 
of the public revenues shock. After the realization of the shock to public revenues, provision of public goods is implemented. This formulation captures in a simple way that shocks to public sector income affects the provision of public goods, since public policies have to be adjusted to satisfy the budget constraint after the shocks. This feature, and our assumption that voters dislike instability in the provision of public goods, will imply a role for price volatility on the reelection probability of the policymaker.

Since politicians belong to one of the groups, they have the same preferences as other members of the group. The per period preferences $V_{t}^{i}$ of a politician $i=A, B$ is given by

$$
V_{t}^{i}=R_{t}^{i}-\gamma^{i} \frac{\left(\bar{G}-G_{t}^{i}\right)^{2}}{2} .
$$

Here $R_{t}^{i}$ denotes the politician's private good consumption, which is determined by how much public resources the politician appropriates for himself.

The per period budget constraint for a politician $i=A, B$ in power is

$$
G_{t}^{A}+G_{t}^{B}+R_{t}^{i}=Z_{t}-W\left(L_{t}^{A}+L_{t}^{B}\right) .
$$

which says that total expenditure on public goods, $G_{t}^{A}+G_{t}^{B}$, plus rent extraction by the politician, $R_{t}^{i}$, must be equal to exogenous government income, $Z_{t}$ minus the wage bill incurred by patronage employment, $W\left(L_{t}^{A}+L_{t}^{B}\right)$.

To find the re-election probability we employ a version of the probabilistic voting model (see Linbeck and Weibull, 1987, Persson and Tabellini, 2000). Each voter $i$ has an ideological bias $s^{i}$ toward the incumbent politician $A$. Denoting $U_{2}^{i}(A)$ the expected future utility of a voter $i$ if the incumbent wins, and $U_{2}^{i}(B)$ if the opposition wins, the voter supports the incumbent if

$$
U_{2}^{i}(A)+s^{i}+\theta>U_{2}^{i}(B) .
$$

We assume that $s^{i}$ is uniformly distributed at the interval $\left[-\frac{1}{2 s}, \frac{1}{2 s}\right]$ with density $s>0$, and that $\theta$ is a random shock affecting the popularity of the incumbent. It is assumed to be uniformly distributed at the interval $\left[-\frac{1}{2 h}, \frac{1}{2 h}\right]$ with density $h>0$.

\subsection{Timing of events and equilibrium}

The timing of the game can be summarized as follows.

- The incumbent politician chooses the policy vector $\left\{R_{1}^{A}, G_{1}^{A}, G_{1}^{B}, L_{1}^{A}, L_{1}^{B}\right\}$ subject to the budget constraint (2).

- First period payoffs are realized.

- Politicians $A, B$ compete in the election by non-cooperatively offering policies $\left\{R_{2}^{A}(A), G_{2}^{A}(A), G_{2}^{B}(A), L_{2}^{A}(A), L_{2}^{B}(A)\right\} \quad$ and $\quad\left\{R_{2}^{B}(B), G_{2}^{A}(B), G_{2}^{B}(B), L_{2}^{A}(B), L_{2}^{B}(B)\right\}$, respectively which again must satisfy $(2)$. 
- Whichever politician wins the election takes power and chooses his rent and public employment.

- There is realization of the revenue shock $\epsilon$.

- Second period revenues are realized, and actual public good provision and consumption takes place for all agents.

Voters realize that for policies to be implemented they have to be ex post optimal for the chosen politician. Politicians cannot credibly commit to policies which are not in their own interest. As usual we find the pure strategy subgame perfect equilibrium, and in the continuation we thus apply backward induction to solve the model.

A full characterization of equilibrium would specify second period policies for any combination of the chosen politician and the first period level of patronage employment from both groups. However, it will become clear below that the incumbent politician $A$ will never offer public employment to voters from group $B$ (as this is costly and will also reduce his reelection probability since these voters realize they will only remain in employment should politician $B$ win the election). Moreover, we have already specified that a politician will not fire workers from his own group should he win the election, but will fire workers from the other group. For these reasons we limit attention to situations where $L_{1}^{B}=L_{2}^{B}(A)=0$ and $L_{2}^{A}(A)=L_{1}^{A}$.

\subsection{Period 2: Credible policies}

The politician who wins the election decides post-election policies.

Consider first the case where the initial opposition politician $B$ is elected. There will not be any patronage employment since such employment is only optimal when there are election incentives and period 2 is the final period. The politician does not provide public goods to group $A$ voters, and thus $G_{2}^{A}(B)=0$. His choice of $R_{2}^{B}(B)$ and $G_{2}^{B}(B)$ is the solution of the following program:

$$
\max _{R_{2}^{B}, G_{2}^{B}} R_{2}^{B}-\gamma^{B} E\left[\frac{\left(\bar{G}-G_{2}^{B}\right)^{2}}{2}\right]
$$

subject to the budget constraint (2), where $E($.$) reflects the expectation operator with respect$ to the public revenue $Z_{2}$. From the budget constraint the level of public goods provided to his group is given by $G_{2}^{B}(B)=\max \left[Z_{2}-R_{2}^{B}(B) ; 0\right]$. To simplify the analysis, we will (in a way to be precisely specified in Assumption A.1 below) only consider regimes in which $G_{2}^{B}(B)>0$ for all realizations of $Z_{2}$. Given the quadratic utility function on the public good, the problem can then be rewritten in terms of certainty equivalent as

$$
\max _{R_{2}^{B}} R_{2}^{B}-\gamma^{B} \frac{\left(\bar{G}-E\left[G_{2}^{B}(B)\right]\right)^{2}}{2}-\gamma^{B} \frac{\sigma^{2}}{2},
$$


with $E\left[G_{2}^{B}(B)\right]=\overline{Z_{2}}-R_{2}^{B}(B)$.

The first order condition for an interior solution can be written as:

$$
1=\gamma^{B}\left(\bar{G}-E\left[G_{2}^{B}(B)\right]\right)
$$

which gives the optimal level of politician $B$ 's rent to be:

$$
R_{2}^{B}(B)=\overline{Z_{2}}+\frac{1}{\gamma^{B}}-\bar{G},
$$

and the level of provision of the public good specific to group $B$ :

$$
G_{2}^{B}(B)=Z_{2}-\overline{Z_{2}}+\bar{G}-\frac{1}{\gamma^{B}}
$$

Consider next the case where the initial incumbent politician $A$ is reelected. Using the same solution procedure as for politician $B$, we find that politician $A$ does not offer public goods to group $B$ voters and hence $G_{2}^{B}(A)=0$. The optimal level of politician $A$ 's rent is given by

$$
R_{2}^{A}(A)=\overline{Z_{2}}-W L_{1}^{A}+\frac{1}{\gamma^{A}}-\bar{G}
$$

and the level of group $A$ specific public goods is

$$
G_{2}^{A}(A)=Z_{2}-\overline{Z_{2}}+\bar{G}-\frac{1}{\gamma^{A}}
$$

The following assumptions are sufficient to ensure that an interior solution $R_{2}^{i}(i)>0$ and $0<G_{2}^{i}(i)<\bar{G}, i=A, B$, always exists:

Assumption A1: $a<\min \left\{\frac{1}{\gamma^{2}} ; \bar{G}-\frac{1}{\gamma^{2}}\right\}$.

Assumption A2: $\overline{Z_{2}}-\frac{W}{2}>\bar{G}-\frac{1}{\gamma^{2}}$.

Assumption A1 says that second period resource price variations are not too large, ensuring that the quantity of the type of public good that is provided is always interior (i.e. $0<G_{2}^{i}(i)<$ $\bar{G})$. Assumption A2. guarantees that the politician in power always obtains a positive rent (i.e. $\left.R_{2}^{i}(i)>0\right)$.

Substitution of the above solutions immediately gives the second period expected utility of private sector voters of type $i \in A, B$ when a politician of type $j \in A, B$ is in power:

$$
U_{2}^{i}(j)=H-\frac{1}{2 \gamma^{i}}-\gamma^{i} \frac{\sigma^{2}}{2} \text { when } i=j \text {, and } U_{2}^{i}(j)=H-\frac{\gamma^{i}}{2}(\bar{G})^{2} \text { when } i \neq j .
$$

Private sector voters have their private consumption equal to their productivity $H$ (as for now there are no taxes). Apart from that term, the expected utility of private sector voters changes with the identity of the politician in office. If the politician from the same group as a 
voter wins the election there is a utility gain of $\frac{\gamma^{i}}{2}(\bar{G})^{2}-\frac{1}{2 \gamma^{i}}$ compared to if the politician from the other group wins the election. However, in that case the voter also face fiscal volatility that reduces his utility by $\gamma^{i} \frac{\sigma^{2}}{2}$.

Too see that the net utility effect of having own politician rather than the other politician win the election is always positive, first note that the condition for utility to be higher when own politician is elected is

$$
\frac{1}{2 \gamma^{i}}+\gamma^{i} \frac{\sigma^{2}}{2}<\frac{\gamma^{i}}{2}(\bar{G})^{2}
$$

which can be reformulated to

$$
\sigma^{2}<(\bar{G})^{2}-\frac{1}{\left(\gamma^{i}\right)^{2}}
$$

Taking into account that the maximum possible variance of a stochastic variable with support on $[-a, a]$ is $a^{2}$, a sufficient condition for this to hold is

$$
a^{2}<(\bar{G})^{2}-\frac{1}{\left(\gamma^{i}\right)^{2}}
$$

At the same time we know from Assumption A1 that $a<\bar{G}-\frac{1}{\gamma^{i}}$, so that a sufficient condition for (8) to hold is that

$$
\left(\bar{G}-\frac{1}{\gamma^{i}}\right)^{2}<(\bar{G})^{2}-\frac{1}{\left(\gamma^{i}\right)^{2}},
$$

which is equivalent to

$$
\bar{G}-\frac{1}{\gamma^{i}}>0 .
$$

In light of Assumption A1 this always holds. Thus we have shown that, despite of the cost of volatility, utility from public goods provision is always strictly higher when a politician from one's own group decides policy.

Similar reasoning allows us to derive the expected utility for public employee voters of group $A$ :

$$
U_{2}^{L}(A)=W-\frac{1}{2 \gamma^{A}}-\gamma^{A} \frac{\sigma^{2}}{2} \text { and } U_{2}^{L}(B)=H-\frac{\gamma^{A}}{2}(\bar{G})^{2},
$$

where the only difference compared to (8) is that private consumption equals the public wage $W$ when the incumbent politician $A$ is reelected.

These expressions reflect the asymmetric commitment capacity between the incumbent $A$ and the challenger $B$. When reelected the incumbent $A$ keeps offering public jobs to his clients in group $A$. These public positions pay a public wage $W$ which is larger than the private sector productivity $H$. Conversely, when getting into power, the challenger $B$ has no interest in giving public sector jobs to any voter as this only reduces what he can get for himself out of the public budget. Individuals of type $A$ having a public sector job from the incumbent in the first period, therefore loose some rent $W-H$ when the politician of type $B$ is in power. Their private consumption is thus higher when their patron wins the election. 


\subsection{Period 1: Voters and the reelection probability of the incumbent}

We are now in a position to compute the probability of reelection of the political incumbent. First, for a given realization of his popularity shock $\theta$, the share of voters from group $B$ that vote for the incumbent politician $A$ are those individuals for whom

$$
U_{t}^{B}(A)+s^{i}+\theta>U_{t}^{B}(B) .
$$

Given (7) this can be reformulated as

$$
s^{i}>-\theta+\left(\frac{\gamma^{B}}{2}(\bar{G})^{2}-\frac{1}{2 \gamma^{B}}-\gamma^{B} \frac{\sigma^{2}}{2}\right),
$$

implying that the share of group $B$ voters that support politician $A$ is given by

$$
\frac{1}{2}+s \theta-s\left(\frac{\gamma^{B}}{2}(\bar{G})^{2}-\frac{1}{2 \gamma^{B}}-\gamma^{B} \frac{\sigma^{2}}{2}\right)
$$

and that the number of group $B$ voters $N_{B}$ that supports $A$ is:

$$
N_{B}=\frac{1}{2}\left(\frac{1}{2}+s \theta-s\left(\frac{\gamma^{B}}{2}(\bar{G})^{2}-\frac{1}{2 \gamma^{B}}-\gamma^{B} \frac{\sigma^{2}}{2}\right)\right) .
$$

Thus, on an expected basis $(\theta=0)$, less than half of the group $B$ voters support the incumbent politician $A$, since when their own politician $B$ wins they enjoy the provision of group specific public goods.

Proceeding in a similar fashion, the number of private sector voters of group $A$ that support the incumbent politician $A$ is given by

$$
N_{A}=\left(\frac{1}{2}-L_{1}^{A}\right)\left(\frac{1}{2}+s \theta+s\left(\frac{\gamma^{A}}{2}(\bar{G})^{2}-\frac{1}{2 \gamma^{A}}-\gamma^{A} \frac{\sigma^{2}}{2}\right)\right),
$$

while the number of public employees of group $A$ that support incumbent $A$ is given by

$$
N_{A}^{P}=L_{1}^{A}\left(\frac{1}{2}+s \theta+s\left(\frac{\gamma^{A}}{2}(\bar{G})^{2}-\frac{1}{2 \gamma^{A}}-\gamma^{A} \frac{\sigma^{2}}{2}\right)+s(W-H)\right)
$$

The last term in this equation $s(W-H)>0$ reflects the rent conferred on public employees of group $A$ when their incumbent patron is reelected. Obviously, the larger this rent the more likely such voters will support the incumbent.

The reelection probability of the incumbent $A$ is

$$
\Pi=\operatorname{Pr}\left\{N_{B}+N_{A}+N_{A}^{P} \geq \frac{1}{2}\right\},
$$

which by inserting from (10), (11) and (12) can be simplified to

$$
\Pi=\operatorname{Pr}\left[\theta \geq-\left(\gamma^{A}-\gamma^{B}\right) \frac{1}{4}\left((\bar{G})^{2}+\frac{1}{\gamma^{A} \gamma^{B}}-\sigma^{2}\right)-(W-H) L_{1}^{A} \geq 0\right] .
$$


Integrating over $\theta$ we obtain:

$$
\Pi=\frac{1}{2}+h\left(\left(\gamma^{A}-\gamma^{B}\right) \frac{1}{4}\left((\bar{G})^{2}+\frac{1}{\gamma^{A} \gamma^{B}}-\sigma^{2}\right)+(W-H) L_{1}^{A}\right) .
$$

There are two noteworthy implications of this reelection probability. First, as expected, it depends positively on the level of public employment $L_{1}^{A}$ that the incumbent allocates in the first period to his clients:

$$
\frac{\partial \Pi}{\partial L_{1}^{A}} \equiv \Pi_{L}=h(W-H)>0 .
$$

This is related to the asymmetric capacity of the incumbent to propose credibly some public sector rents to his clients in group $A$. This produces an incumbency bias. Having political power allows the incumbent to tie the continuation utility of some voters to his own political success.

Second, we see that in general the probability of reelection depends on the volatility of the resource price:

$$
\frac{\partial \Pi}{\partial \sigma^{2}} \equiv \Pi_{\sigma^{2}}=-h\left(\gamma^{A}-\gamma^{B}\right) \frac{1}{4} .
$$

To see the intuition behind this result, consider the case where the provision of public goods is more important for group $A$ than for group $B$ voters, i.e. $\gamma^{A}>\gamma^{B}$. We then note that $\Pi_{\sigma^{2}}<0$. Conditional on the public good of a group being provided, voters suffer a utility loss which is increasing in the volatility of the provision. This utility loss is higher the more important the provision of the public good is. Thus, although increased volatility makes the utility of both voter groups less tied to the political success of their own politician, the fall in support is greater for politician $A$ than for politician $B$. It follows that the incumbent's probability of reelection $\Pi$ is decreasing in public revenue volatility when the incumbent belongs to the group where public provision is most needed. If, on the other hand, the incumbent belongs to the group where public provision is least needed, his election probability is increasing in volatility. This result captures therefore in a simple manner the fact that revenue volatility has an impact on political turnover. In this sense, political uncertainty connects to economic uncertainty. We also note that this connection is stronger the higher is the heterogeneity in preferences between groups, i.e. the higher is the absolute value of $\gamma^{A}-\gamma^{B}$.

\subsection{Period 1: Policy of the incumbent}

Inserting from (5) and (6) into the utility function of the incumbent politician $A$, the incumbent solves the optimization program:

$$
\max _{R_{1}^{A}, G_{1}^{A}, L_{1}^{A}} R_{1}^{A}-\gamma^{A} \frac{\left(\bar{G}-G_{1}^{A}\right)^{2}}{2}+\Pi\left[\overline{Z_{2}}-W L_{1}^{A}+\frac{1}{2 \gamma^{A}}-\bar{G}-\gamma^{A} \frac{\sigma^{2}}{2}\right]+(1-\Pi)\left[-\frac{\gamma^{A}}{2}(\bar{G})^{2}\right],
$$

subject to $\Pi$ being given by (13), and the budget constraint:

$$
G_{1}^{A}+R_{1}^{A}=Z_{1}-W L_{1}^{A}
$$


The level of provision of the public good specific to group $A$ in period 1 is given by

$$
G_{1}^{A}=\bar{G}-\frac{1}{\gamma^{A}}>0
$$

while the incumbent politician's rent is

$$
R_{1}^{A}=Z_{1}-W L_{1}^{A}+\frac{1}{\gamma^{A}}-\bar{G}>0
$$

The equilibrium level of public (patronage) employment is the solution of the first order condition:

$$
\Pi_{L}^{\prime}\left(\overline{Z_{2}}-W L_{1}^{A}+\frac{1}{2 \gamma^{A}}-\bar{G}-\gamma^{A} \frac{\sigma^{2}}{2}+\frac{\gamma^{A}}{2}(\bar{G})^{2}\right)-W(1+\Pi)=0 .
$$

The solution of this equation provides the equilibrium level $L_{1}^{A}$ of clientelistic public jobs. The first term $\Pi_{L}^{\prime}\left(\overline{Z_{2}}-W L_{1}^{A}+\frac{1}{2 \gamma^{A}}-\bar{G}-\gamma^{A} \frac{\sigma^{2}}{2}+\frac{\gamma^{A}}{2}(\bar{G})^{2}\right)$ reflects the marginal benefit of political patronage. It is given by the marginal probability of reelection $\Pi_{L}^{\prime}$ associated with a public job, multiplied by the term in bracket reflecting the utility value for the incumbent of staying in power in the second period.

The second term $W[1+\Pi]$ is the expected resource cost for the incumbent to offer a public job. As the incumbent commits to public positions while in power, this resource cost has to be paid in the first period and in expected terms in the second period. The larger the probability of reelection $\Pi$, the larger this cost. At equilibrium the marginal benefit of patronage has to be equal to its marginal cost. ${ }^{4}$

\subsection{Revenue volatility and policy efficiency}

We are now ready to investigate the effect of revenue volatility on the political and economic equilibrium. The following proposition summarizes our first main result:

Proposition 1 Higher volatility in public revenues, that is an increased $\sigma^{2}$, increases patronage employment $L_{1}^{A}$ when and only when

$$
\frac{2 \gamma^{A}}{\gamma^{A}+\gamma^{B}}>\frac{W}{H}
$$

Proof. We first differentiate (17) to obtain

$$
\frac{\partial L_{1}^{A}}{\partial \sigma^{2}}=\frac{-\Pi_{L}^{\prime} \frac{\gamma^{A}}{2}-W \Pi_{\sigma^{2}}^{\prime}}{2 W \Pi_{L}^{\prime}} .
$$

Inserting from (14) and (15) we find

$$
\frac{\partial L_{1}^{A}}{\partial \sigma^{2}}=\frac{\gamma^{A} H-\frac{W}{2}\left(\gamma^{A}+\gamma^{B}\right)}{4 W(W-H)},
$$

\footnotetext{
${ }^{4}$ Note that the second order condition for $L_{1}^{A}$ writes as $-2 W \Pi_{L}^{\prime}=-2 W h(W-H)<0$ and is therefore satisfied.
} 
which is negative when and only when (18) holds.

The proposition shows that when the politician from the group that values publicly provided goods the highest holds political power, then patronage employment increases with revenue volatility if policy preferences are sufficiently heterogenous between groups, and/or if public wages are not too high compared to private sector productivity. The intuition for this is that, on the one hand, more fiscal volatility reduces the value to be in power for the incumbent, and therefore induces a lower level of clientelistic public employment $L_{1}^{A}$ associated to secure such reelection. On the other hand, however, higher revenue volatility implies a lower future utility also of the voters in his group if he wins future political power, and thus reduces his probability $\Pi$ of reelection. In turn, this reduces the expected cost of public jobs, and promotes the use of public employment as an instrument of political patronage to push his reelection probability back up. If the latter effect is the strongest, then patronage employment increases.

A first corollary to Proposition 1 is that:

Corollary 1 Aggregate income in the present decreases with higher volatility if and only if patronage employment increases.

Proof. The effect on current income $Y_{1}=H+Z_{1}-L_{1}^{A} H$ of increased volatility is given by

$$
\frac{\partial Y_{1}}{\partial \sigma^{2}}=-H \frac{\partial L_{1}^{A}}{\partial \sigma^{2}}
$$

and thus increased revenue volatility push current income down if and only if it induces higher patronage employment.

This corollary shows that the effect on aggregate income from volatility in our basic model works exclusively through the effect on policy inefficiency due to patronage.

A second corollary to Proposition 1 is that:

Corollary 2 When there is no heterogeneity in the valuation of public goods, i.e. $\gamma^{A}=\gamma^{B}$, increased revenue volatility reduces patronage employment.

Proof. This follows by noting that when $\gamma^{A}=\gamma^{B}$ (18) reduces to $H>W$, which is always true.

Therefore, the possibility of increased policy inefficiency with higher revenue volatility is intimately linked to the polarization of preferences. Moreover, maybe paradoxically, for policy inefficiency to increase with revenue volatility, it has to be the group that values public provision the most that holds power.

We can also find the effect on total expected aggregate income over the two periods, $Y_{1}+Y_{2}$, given by

$$
Y_{1}+Y_{2}=2 H+p_{1} Z+\overline{p_{2}} Z-(1+\Pi) L_{1}^{A} H
$$


Taking into account that $\Pi$ is determined by (13), an increase in the volatility gives

$$
\frac{\partial\left(Y_{1}+Y_{2}\right)}{\partial \sigma^{2}}=-\left(1+\Pi+\Pi_{L}^{\prime} L_{1}^{A}\right) H \frac{\partial L_{1}^{A}}{\partial \sigma^{2}}-L_{1}^{A} H \Pi_{\sigma^{2}}^{\prime} .
$$

Thus there are two effects from increased volatility on the net present value of expected aggregate income. First, as above, if volatility stimulates patronage this pulls in the direction of decreased total income. Second, since higher volatility reduces the reelection probability of the incumbent, it decreases the likelihood that there is patronage employment in the second period, pulling in the direction of increased expected total income. ${ }^{5}$

\subsection{Extension: public investment}

A possible concern with our basic model is that we assumed the policy space to be restricted to targeted public goods and inefficient patronage employment. We did not have the possibility of efficient policies that benefitted the society at large. A key question is if the possibilities of such policies mean that inefficient policy does not longer prevail, or is weakened, in political equilibrium. We now turn to this question.

Consider thus the case where the policy space is expanded to include general public investments $I$ that increase the productivity of all workers in the private sector. Let $H_{t}$ denote private sector productivity in period $t$, which is now given by

$$
H_{1}=H \quad ; \quad H_{2}(I)=H+\delta I,
$$

with $\delta>0$. We also now take into account that the government can tax the private sector with some tax rate $\tau \in[0,1]$.

In the second period the budget constraint for a politician $i=A, B$ in power is

$$
G_{2}^{A}+G_{2}^{B}+R_{2}^{i}=Z_{2}+\tau H_{2}\left(1-L_{2}^{A}(i)\right)-W L_{2}^{A}(i) .
$$

The budget constraint now captures the fact that taxes $\tau H_{2}\left(1-L_{t}^{A}(i)\right)$ can be collected from the private sector. In the second period politician $B$ (if in power) as before maximizes (4), but now subject to the budget constraint (21). This gives the rent to politician $B$ as

$$
R_{2}^{B}(B)=\overline{Z_{2}}+\tau H_{2}+\frac{1}{\gamma^{B}}-\bar{G}
$$

\footnotetext{
${ }^{5}$ Again the effect on income will be negative when the wage gap between the private and public sector is not too large, since by inserting for $\Pi_{L}^{\prime}, \frac{\partial L_{1}^{A}}{\partial \sigma^{2}}$, and $\Pi_{\sigma^{2}}^{\prime}$ in (19) the condtion for this reduces to

$$
-\left(\frac{3}{2}+h\left(\gamma^{A}-\gamma^{B}\right) \frac{1}{4}\left[(\bar{G})^{2}+\frac{1}{\gamma^{A} \gamma^{B}}-\sigma^{2}\right]\right)\left(\gamma^{A} H-\frac{W}{2}\left(\gamma^{A}+\gamma^{B}\right)\right)+2 \gamma^{A} h L_{1}^{A}(W-H)^{2}<0,
$$

which will be fulfilled if $\gamma^{A}>\gamma^{B}$ and $W-H$ is sufficiently small.
} 
and the level of provision of the public good specific to group $B$ as

$$
G_{2}^{B}(B)=Z_{2}-\overline{Z_{2}}+\bar{G}-\frac{1}{\gamma^{B}}
$$

Similarly, if politician $A$ holds power in the second period his rent is given by

$$
R_{2}^{A}(A)=\overline{Z_{2}}+\tau H_{2}\left(1-L_{1}^{A}\right)-W L_{1}^{A}+\frac{1}{\gamma^{B}}-\bar{G},
$$

which captures the fact that $L_{1}^{A}$ public jobs are maintained as a result of political patronage. The level of group $A$ specific public goods is given by the formula

$$
G_{2}^{A}(A)=Z_{2}-\overline{Z_{2}}+\bar{G}-\frac{1}{\gamma^{B}} .
$$

Again we assume interior solutions for public goods provision and rent for all realized values of $Z_{2}$ (as implied by assumptions A1 and A2).

It can easily be seen that utilities of voters are again given by (7) for private sector voters and by (9) for public employee voters (where in both expressions $H$ is now replaced by $(1-\tau) H_{2}$ ).

Following the same procedure as in the previous section, one can derive the probability of reelection of the incumbent politician to be:

$$
\Pi=\frac{1}{2}+h\left(\left(\gamma^{A}-\gamma^{B}\right) \frac{1}{4}\left((\bar{G})^{2}+\frac{1}{\gamma^{A} \gamma^{B}}-\sigma^{2}\right)+\left(W-H_{2}(I)(1-\tau)\right) L_{1}^{A}\right) .
$$

As before this probability is increasing in public jobs $L_{1}^{A}$ provided by political patronage. Interestingly, it is decreasing in the level of general public investment $I$. A higher value of $I$ reduces the difference $W-H_{2}(I)(1-\tau)$ ) between a public job and a position in the private sector. This in turn reduces the effectiveness of political patronage, as each public employee from group $A$ has less to loose when the incumbent is not reelected. As a consequence there is a lower number of voters of type $A$ supporting the incumbent, and the probability $\Pi$ of staying in power is reduced. Thus, other things equal, poverty makes patronage more politically efficient for the incumbent. And, paradoxically, since the political survival probability decreases with investment, investing for the future actually shortens the horizon of the politician in the sense that the future is discounted by more.

The first period problem of the incumbent can now be expressed as:

$$
\begin{aligned}
& \max _{R_{1}^{A}, G_{1}^{A}, L_{1}^{A}, I} R_{1}^{A}-\gamma \frac{\left(\bar{G}-G_{1}^{A}\right)^{2}}{2} \\
& +\Pi\left(\overline{Z_{2}}+\tau H_{2}\left(1-L_{1}^{A}\right)-W L_{1}^{A}+\frac{1}{2 \gamma^{A}}-\bar{G}-\gamma^{A} \frac{\sigma^{2}}{2}\right)+(1-\Pi)\left(-\frac{\gamma}{2}(\bar{G})^{2}\right)
\end{aligned}
$$

subject to $H_{2}$ being given by (20), $\Pi$ being given by (22), and the budget constraint

$$
G_{1}^{A}+R_{1}^{A}=Z_{1}+\tau H_{1}\left(1-L_{1}^{A}\right)-W L_{1}^{A}-I .
$$


Again the level of provision of the public good specific to group $A$ in period 1 can be written as

$$
G_{1}^{A}=\bar{G}-\frac{1}{\gamma^{A}}
$$

while the rent captured by the incumbent is now

$$
R_{1}^{A}=Z_{1}+\tau H_{2}\left(1-L_{1}^{A}\right)-W L_{1}^{A}-I+\frac{1}{\gamma^{A}}-\bar{G} .
$$

The equilibrium levels of the two remaining variables, public employment $L_{1}^{A}$ and public investment $I$, are, respectively, determined simultaneously by the following two first order conditions:

$$
\begin{gathered}
-\left(W+\tau H_{1}\right)-\Pi\left(W+\tau H_{2}\right)+\Pi_{L}^{\prime}\left[V_{\text {power }}\right]=0, \\
-1+\Pi_{I}^{\prime}\left[V_{\text {power }}\right]+\Pi \tau \delta\left(1-L_{1}^{A}\right)=0,
\end{gathered}
$$

with

$$
V_{\text {power }}=\overline{Z_{2}}+\tau H_{2}\left(1-L_{1}^{A}\right)-W L_{1}^{A}+\frac{1}{2 \gamma^{A}}-\bar{G}-\gamma^{A} \frac{\sigma^{2}}{2}+\frac{\gamma^{A}}{2}(\bar{G})^{2} .
$$

capturing the utility value of staying in power for the incumbent. Equation (23) defines the optimal level of public employment $L_{1}^{A}(I)$ for a given level of public investment $I$. The marginal cost of public employment now includes in each period $t$ the public wage $W$ plus the lost tax revenue $\tau H_{t}$ that such a job would have created in the private sector. For the second period the cost has to be discounted by the probability of reelection $\Pi$ of the incumbent. The marginal benefit of political patronage is as before the product of the marginal impact of public employment on the reelection probability $\Pi_{L}^{\prime}$ multiplied by the net utility gain for the incumbent to remain in power $V_{\text {power }}$. This last term now includes tax revenues from the private sector $\tau H_{2}\left(1-L_{1}^{A}\right)$.

Equation (24) defines the optimal level of public investment $I\left(L_{1}^{A}\right)$ for a given level of public employment $L_{1}^{A}$. The first two terms reflect the marginal cost of public investment. The first term is the resource cost 1 of public investment on the first period budget. The second term reflects the fact that public investment decreases the probability of reelection $\left(\Pi_{I}^{\prime}<0\right)$, and losing the election has a cost $V_{\text {power }}$ for the incumbent. The last term in (24) $\Pi \tau \delta\left(1-L_{1}^{A}\right)$ reflects the marginal gain to public investment for the incumbent. Investment yields increased tax revenue $\tau \delta\left(1-L_{1}^{A}\right)$ obtained from productivity growth $\delta$, and with the probability of reelection $\Pi$, the incumbent can reap the gains from this productivity growth.

\section{Equilibrium patronage and investment}

We now investigate how political patronage and public investment relate to each other, before we turn to the effect of public income volatility on the political economic equilibrium. To find 
the interdependence between patronage and investment we need to investigate the sign of the variation of $L_{1}^{A}(I)$ and $I\left(L_{1}^{A}\right)$. Consider first optimal public employment $L_{1}^{A}(I)$. We show in the Appendix that the sign of $\partial L_{1}^{A}(I) / \partial I$ is determined by the sign of the following expression:

$$
-\Pi_{I}\left(W+\tau H_{2}\right)-\Pi \tau \delta+\Pi_{L}^{\prime} \tau \delta\left(1-L_{1}^{A}\right)+\Pi^{\prime \prime}{ }_{L I}\left[V_{\text {power }}\right]
$$

Several effects are at play. The first two terms reflect two opposite effects of an increase in $I$ on the resource cost of public jobs. First, an increase in public investment $I$ leads to a reduction of $\Pi$ which decreases the expected cost of political patronage and therefore stimulates the provision of public employment $L_{1}^{A}$ (the term $-\Pi_{I}\left(W+\tau H_{2}\right)>0$ ). Second, a higher value of $I$ also boosts private sector productivity $H_{2}$ by the factor $\delta$. As reflected by the term $-\Pi \tau \delta<0$, this increases the opportunity cost of a public job in terms of expected lost tax revenue in the second period, leading incumbent to reduce his optimal level of $L_{1}^{A}$.

The third and fourth terms in (25) reflect the impact of $I$ on the benefits of public jobs, again with two effects pulling in opposite directions. First, an increase in $I$ means higher future tax revenues and thus makes it more attractive to tilt the reelection probability by increasing patronage as seen by the term $\Pi_{L}^{\prime} \tau \delta\left(1-L_{P}\right)>0$. On the other hand, however, a higher value of $I$ makes patronage less politically efficient in terms attracting votes because the income of private sector employment increases. This makes patronage employment less attractive for the incumbent, as seen by the term $\Pi "{ }_{L I}\left[V_{\text {power }}\right]<0$

Consider next optimal public investment $I\left(L_{1}^{A}\right)$. As we show in the Appendix the sign of $\partial I\left(L_{1}^{A}\right) / \partial L_{1}^{A}$ is also determined by the sign of $(25)$, now with the following intuition: the first term reflects the fact that an increase in $L_{1}^{A}$ reduces the value of staying in power by $W+\tau H_{2}$. This makes the decrease in the reelection probability induced by investment less costly, and leads therefore to increased incentives for the provision of $I$. The second term reflects the fact that a larger value of $L_{1}^{A}$ reduces the size of the private sector, and therefore should the incumbent win there are less private sector employees to tax, making productivity enhancing investments less attractive. The third term captures the effect that higher public employment increases the probability of staying in power, and thus makes productivity enhancing investments more attractive as the incumbent is more likely to receive the gains of higher taxes. Finally, as shown by the fourth term, an increase in $L_{P}$ makes the reduction in the reelection probability by investment larger, inducing the incumbent to reduce the optimal level of investment.

Thus in general we have two cases, one where the two variables are positively related to each other from both of the first order conditions, and one where they are negatively related to each other. Since what we are concerned with here is countries where political power is highly attractive, so that $V_{\text {power }}$ is typically large, we focus on the case where the value of public income $\overline{Z_{2}}$ is sufficiently large to make the term $\Pi^{\prime \prime}{ }_{I L}\left[V_{\text {power }}\right]<0$ dominate (see the Appendix for the precise condition for this). In such a case, political patronage and public investment are 
strategic substitutes: an increase in one variable tends to decrease the optimal level of the other variable. This is shown by the solid curves in Figure 1, plotting the two curves $L_{1}^{A}(I)$ and $I\left(L_{1}^{A}\right)$ in the plane $\left(L_{1}^{A}, I\right) .{ }^{6}$ As discussed in the Appendix, we assume for this purpose that the second order conditions of the incumbent's maximization problem are satisfied. This implies that the curve $L_{1}^{A}(I)$ has a steeper slope than the curve $I\left(L_{1}^{A}\right)$. The intersection at point $E$ provides the optimal levels of public employment and investment of the incumbent.

\section{Figure 1 about here.}

\section{Revenue volatility and policy efficiency}

We can now study the effect of revenue volatility on the political economic equilibrium. Again let us start with political patronage $L_{1}^{A}(I)$. In the Appendix we show through differentiation of (23) that the curve $L_{1}^{A}(I)$ shifts to the right with increased revenue volatility when

$$
\frac{2 \gamma^{A}}{\gamma^{A}+\gamma^{B}}>\frac{W}{H_{2}}+\tau
$$

As in the basic model section, when $\gamma^{A}>\gamma^{B}$ two effects pull political patronage in different directions. First, an increase of $\sigma^{2}$ leads to more political turnover, reducing the expected cost of public jobs for the incumbent, and thus stimulates the expansion of the public sector. Second, higher price volatility translates into more fiscal volatility for public good provision, and this reduces the utility value of the incumbent to stay in power, in turn weakening the incentives for political patronage. Thus again when the polarization of preferences is high relative to the wage gap between the public sector and the private sector, the positive effect outweighs the negative one: volatility then leads to more political patronage and the curve $L_{1}^{A}(I)$ shifts to the right.

Similarly in the Appendix we show by differentiation of (24) that the curve $I\left(L_{1}^{A}\right)$ shifts down if

$$
\frac{\tau\left(1-\frac{\gamma^{B}}{\gamma^{A}}\right)}{2+\tau\left(1+\frac{\gamma^{B}}{\gamma^{A}}\right)}>L_{1}^{A} .
$$

On the one hand, as higher price volatility translates into higher political turnover, the marginal benefit of public investment on expected tax revenues of the second period is reduced for the incumbent. This tends to reduce the chosen level of public investment by the politician. On the other hand, an increase in volatility reduces the utility value of staying in power for the incumbent, and therefore the reduction in reelection probability that investment induces becomes less problematic for the incumbent, pulling in the direction of increased investment. When the size of the public sector is not too large compared to fiscal capacity $\tau$, and when the

\footnotetext{
${ }^{6}$ The case where the two variables are positively related to each other can be studied with a similar figure, where both curves are upward sloping.
} 
polarization of preferences is strong, the negative effect of volatility outweighs the positive one, and an increase in $\sigma^{2}$ then leads to a reduction of public investment and a thus to a downward shift of the $I\left(L_{1}^{A}\right)$-curve.

Under these conditions therefore, the shift in the curves are as drawn by the dotted curves in Figure 1. The full impact of increased price volatility is to shift the equilibrium policy point from $E$ to $E^{\prime}$. Again, there is increased patronage employment and decreased investment. Moreover, the increase in patronage stimulates the decrease in investments, at the same time as the decrease in investments stimulates the increase in patronage employment.

Paradoxically, therefore, in exactly the circumstances where increased volatility reduced policy efficiency in the basic model, extending the policy space to allow for general public investments that benefit a broad cross section of society actually makes the problem worse.

It is easy to see that such a case is disastrous for national income and growth. Indeed expected national wealth over the two periods is:

$$
Y_{1}+Y_{2}=H_{1}\left(1-L_{1}^{A}\right)+Z_{1}+H_{2}(I)\left(1-\Pi\left(L_{1}^{A}\right) L_{1}^{A}\right)+\overline{Z_{2}} .
$$

Compared to in our basic model it is a simple matter to see that increased revenue volatility now has three effects pulling $Y_{1}+Y_{2}$ down. First, there is even less private sector employment. Second, the reelection probability of the incumbent increases compared to that in the basic model, making it less likely that labor allocation is efficient in the second period. Third, investment, and thus future productivity, is reduced. For these reasons, increased revenue volatility may have a strong negative effect on income if institutions cannot prevent politicians from undertaking patronage employment.

\section{Application: volatility and the resource curse}

We now extend and apply our approach to study a particular form of public sector income volatility, namely that related to the extraction of natural resources. We study how price volatility affects resource extraction, compare this to the social efficient extraction path, and discuss the interplay between resource extraction, political patronage and price volatility. To show the new effects this introduces, we first analyze the model without patronage. We then extend the analysis to include patronage, and show that in such a case volatility may produce a resource curse both as a result of higher overextraction and more patronage employment.

\subsection{Introducing resource extraction}

The physical quantity of the resource extracted in the first period is denoted $e$. In the period after the election there is $R(e)$ left of the resource, with $R^{\prime}<0$ and $R^{\prime \prime}<0$. The intertemporal path of prices $\left(p_{1}, p_{2}\right)$ is determined on world markets and taken as given by our small open 
economy. Thus we now have public revenue in period 1 given by $Z_{1}=p_{1} e$, and public revenue in period 2 given by $Z_{2}=p_{2} R(e)$. We shall assume that $p_{1}=\overline{p_{1}}>0$ is deterministic and that $p_{2}$ is stochastic and such that $p_{2}=\overline{p_{2}}+\epsilon_{p}$ with $\overline{p_{2}}>0$ and $\epsilon_{p}$ a random variable defined on $\left[-a_{p}, a_{p}\right]$ such that $E\left(\epsilon_{p}\right)=0$ and $\operatorname{var}\left(\epsilon_{p}\right)=\sigma_{p}^{2}$. Before the election the incumbent now faces the problem of choosing the same variables as in the basic model, but in addition has to choose the path of resource extraction.

Taking into account that $Z_{2}=p_{2} R(e)$, the reelection probability of the incumbent is now given by:

$$
\Pi=\frac{1}{2}+h\left(\left(\gamma^{A}-\gamma^{B}\right) \frac{1}{4}\left((\bar{G})^{2}+\frac{1}{\gamma^{A} \gamma^{B}}-\sigma^{2} R(e)^{2}\right)+(W-H) L_{1}^{A}\right) .
$$

Simple inspection shows that $\Pi_{e}^{\prime}>0$ if $\gamma^{A}>\gamma^{B}$, while $\Pi_{e}^{\prime}<0$ if the opposite holds. To see the intuition, consider the case of $\gamma^{A}>\gamma^{B}$. Conditional on having the incumbent in power, voters of type $A$ suffer a utility cost of the fiscal volatility associated with the resource price volatility (that exceeds the cost faced by voters of type $B$ ). This cost is positively related to the stock of the resource in the second period. As a consequence, quicker extraction in the first period leaves the voters less exposed to price volatility, and therefore promotes political support for the incumbent. Specifically, one has

$$
\Pi_{e}^{\prime}=-h\left(\gamma^{A}-\gamma^{B}\right) \frac{1}{2} \sigma^{2} R(e) R^{\prime}(e),
$$

and

$$
\Pi_{e \sigma^{2}}^{\prime \prime}=-h\left(\gamma^{A}-\gamma^{B}\right) \frac{1}{2} R(e) R^{\prime}(e),
$$

showing that this effect stronger when the volatility parameter $\sigma^{2}$ is larger.

It should be noted, however, that when $\gamma^{A}>\gamma^{B}$ volatility still affects negatively the capacity of the incumbent to stay in power, since

$$
\Pi_{\sigma^{2}}^{\prime}=-h\left(\gamma^{A}-\gamma^{B}\right) \frac{1}{4} R(e)^{2} .
$$

The first period program of the incumbent can now be written as :

$$
\begin{aligned}
& \max _{R_{1}^{A}, G_{1}^{A}, L_{1}^{A}, e} R_{1}^{A}-\gamma^{A} \frac{\left(\bar{G}-G_{1}^{A}\right)^{2}}{2} \\
& +\Pi\left[\overline{p_{2}} R(e)-W L_{1}^{A}+\frac{1}{2 \gamma^{A}}-\bar{G}-\gamma^{A} \frac{\sigma^{2}}{2} R(e)^{2}\right]+(1-\Pi)\left[-\frac{\gamma^{A}}{2}(\bar{G})^{2}\right]
\end{aligned}
$$

subject to $\Pi$ being given by (26), and the budget constraint

$$
G_{1}^{A}+R_{1}^{A}=p_{1} e-W L_{1}^{A}
$$


To provide a better intuition of the different effects introduced when resource extraction is endogenous, we study two versions of this model. First we assume that patronage employment is not possible, so that $L_{1}^{A}=0$. Next we study the case where the incumbent can also use patronage employment.

\subsection{Resource extraction without patronage employment}

When $L_{1}^{A}=0$ we can, as before, readily compute the optimal interior levels of the incumbent's rent $R_{1}^{A}=p_{1} e+\frac{1}{\gamma^{A}}-\bar{G}$ and group specific public goods $G_{1}^{A}=\bar{G}-\frac{1}{\gamma^{A}}$. More interestingly, we can now compare the extraction path in the political equilibrium with the socially efficient extraction path. We first state the main proposition with its proof, before we turn to four corollaries that trace out and explains the reasons that the two paths differ.

Proposition 2 (i) The political equilibrium path of resource extraction, $e^{*}$, is given by

$$
p_{1}+\overline{p_{2}} R^{\prime}\left(e^{*}\right)-(1-\Pi) \overline{p_{2}} R^{\prime}\left(e^{*}\right)-\Pi \gamma^{A} \sigma^{2} R\left(e^{*}\right) R^{\prime}\left(e^{*}\right)+\Pi_{e}\left(V_{\text {power }}\right)=0,
$$

with the net utility value to stay in power for the incumbent

$$
V_{\text {power }}=\overline{p_{2}} R\left(e^{*}\right)+\frac{1}{2 \gamma^{A}}-\bar{G}-\gamma^{A} \frac{\sigma^{2}}{2} R\left(e^{*}\right)^{2}+\frac{\gamma^{A}}{2}(\bar{G})^{2} .
$$

(ii) The socially efficient path of resource extraction is given by

$$
p_{1}+\overline{p_{2}} R^{\prime}\left(e^{f}\right)-\frac{\gamma^{A} \gamma^{B}}{2\left(\gamma^{A}+\gamma^{B}\right)} \sigma^{2} R\left(e^{f}\right) R^{\prime}\left(e^{f}\right)=0 .
$$

Proof. The optimal extraction path from the point of view of the incumbent is given by the derivative of (27) with respect to $e$ (taking into account $L_{1}^{A}=0,(26)$ and (28)), which gives the following first order condition:

$$
p_{1}+\Pi_{e}\left(V_{\text {power }}\right)+\Pi\left(\overline{p_{2}}-\gamma^{A} \sigma^{2} R(e)\right) R^{\prime}(e)=0,
$$

The second order condition for an optimum is given by:

$$
Q=2 \Pi_{e}^{\prime}\left[\overline{p_{2}}-\gamma^{A} \sigma^{2} R(e)\right] R^{\prime}(e)+\Pi\left[\overline{p_{2}}-\gamma^{A} \sigma^{2} R(e)\right] R^{\prime \prime}(e)-\Pi \gamma^{A} \sigma^{2} R^{\prime}(e)^{2}+\Pi_{e e}^{\prime \prime}\left(V_{\text {power }}\right)<0,
$$

that we assume to be satisfied. ${ }^{7}$ Rearranging (31) yields (29), which proves part (i).

To see part (ii), denote by $X_{t}$ total private consumption in the economy at time $t=1,2$. Note that since utility is linear in private consumption, all possible distributions of a given amount of private consumption between agents yields the same total utility. Therefore, without loss of any generality, when we consider the utilitarian social welfare function we can restrict

\footnotetext{
${ }^{7}$ The three first terms on the right hand side are all negative. Thus a sufficient (but not necessary) condition for this is that $\Pi_{e e}^{\prime \prime}<0$ so that the fourth term is also negative.
} 
ourselves to deal with total private consumption in each period, and not its distribution between different agents in society. Given this, and given that the mass of voters in each group $A, B$ equals $\frac{1}{2}$, the social welfare function, denoted $S$, is given by:

$S=X_{1}+\frac{1}{2}\left(-\frac{\gamma^{A}\left(\bar{G}-G_{1}^{A}\right)^{2}+\gamma^{B}\left(\bar{G}-G_{1}^{B}\right)^{2}}{2}\right)+E\left(X_{2}+\frac{1}{2}\left(-\frac{\gamma^{A}\left(\bar{G}-G_{2}^{A}\right)^{2}+\gamma^{B}\left(\bar{G}-G_{2}^{B}\right)^{2}}{2}\right)\right)$.

The resource constraints are given by

$$
X_{1}+G_{1}^{A}+G_{1}^{B}=p_{1} e \text { and } X_{2}+G_{2}^{A}+G_{2}^{B}=p_{2} R(e) .
$$

The socially efficient policy is found by maximizing $S$ with respect to $\left\{e, G_{1}^{A}, G_{1}^{B}, G_{2}^{A}, G_{2}^{B}, X_{1}, X_{2}\right\}$ subject to (32) (and the requirement that $X_{2}$ must decided before the realization of the price shock $p_{2}$ ).

It is straight forward to find that the provision of public goods between groups $A$ and $B$ is such that

$$
G_{t}^{B}=\bar{G}-\frac{\gamma^{A}}{\gamma^{B}}\left(\bar{G}-G_{t}^{A}\right), t=1,2,
$$

i.e. that the group that values the public goods the most will also receive the highest provision. Inserting this, and inserting from (32), the maximization program can be reformulated as

$$
\begin{aligned}
& \max _{G_{1}^{A}, e, X_{2}}\left(p_{1} e-G_{1}^{A}-\bar{G}+\frac{\gamma^{A}}{\gamma^{B}}\left(\bar{G}-G_{t}^{A}\right)\right)-\frac{\gamma^{A}\left(\gamma^{A}+\gamma^{B}\right)}{4 \gamma^{B}}\left(\bar{G}-G_{1}^{A}\right)^{2} \\
& +X_{2}-\left(\frac{\gamma^{A}\left(\gamma^{A}+\gamma^{B}\right)}{4 \gamma^{B}}\left(\bar{G}-E\left[G_{2}^{A}\right]\right)^{2}-\frac{\gamma^{A} \gamma^{B}}{4\left(\gamma^{A}+\gamma^{B}\right)} \sigma^{2} R(e)^{2}\right)
\end{aligned}
$$

subject to

$$
E\left[G_{2}^{A}\right]=\frac{\gamma^{B}}{\gamma^{A}+\gamma^{B}}\left(\overline{p_{2}} R(e)-X_{2}\right)+\frac{\gamma^{A}-\gamma^{B}}{\gamma^{A}+\gamma^{B}} \bar{G}
$$

The first order conditions for $G_{1}^{A}, X_{2}$ and the extraction path $e$ are:

$$
\begin{gathered}
1=\gamma^{A} \frac{\left(\bar{G}-G_{1}^{A}\right)}{2}, \\
1=\frac{\gamma^{A}}{2}\left(\bar{G}-E\left[G_{2}^{A}\right]\right),
\end{gathered}
$$

and

$$
p_{1}+\frac{\gamma^{A}}{2}\left(\bar{G}-E\left[G_{2}^{A}\right]\right) \overline{p_{2}} R^{\prime}(e)-\frac{\gamma^{A} \gamma^{B}}{2\left(\gamma^{A}+\gamma^{B}\right)} \sigma^{2} R(e) R^{\prime}(e)=0 .
$$

Inserting from (34) in (35) we obtain the characterization of the efficient extraction path $e^{f}$ given by equation (30), which proves part (ii) of the proposition.

A first corollary to Proposition 2 is that in the political equilibrium the politician in power discounts the future too much: 
Corollary 3 Assume there is no resource price volatility $\left(\sigma^{2}=0\right)$. Then the political equilibrium features overextraction of resources compared to the socially efficient extraction path, i.e. $e^{*}>e^{f}$.

Proof. When $\sigma=0$ (29) and (30), respectively, rewrite as:

$$
p_{1}+\overline{p_{2}} R^{\prime}(e *)=(1-\Pi) \overline{p_{2}} R^{\prime}\left(e^{*}\right)<0
$$

and

$$
p_{1}+\overline{p_{2}} R^{\prime}\left(e^{f}\right)=0
$$

Since $\Pi<1$ the corollary follows.

This corollary shows that political uncertainty makes the politician bias the extraction path towards the present, and resembles the result of Robinson, Torvik and Verdier $(2006,2014)$ that there is overextraction of natural resources in political equilibrium. This result is of course a simple version of the results we discussed in the introduction where the presence of elections induces political incumbents to discount the future too highly.

A second corollary to Proposition 2 is that:

Corollary 4 When there is resource price volatility $\left(\sigma^{2}>0\right)$, the socially efficient extraction path is tilted towards the present.

Proof. This follows by noting that when $\sigma^{2}>0$ we have from (30) that

$$
p_{1}+\overline{p_{2}} R^{\prime}\left(e^{f}\right)=\frac{\gamma^{A} \gamma^{B}}{2\left(\gamma^{A}+\gamma^{B}\right)} \sigma^{2} R\left(e^{f}\right) R^{\prime}\left(e^{f}\right)<0
$$

This corollary resembles the van der Ploeg (2010) effect, which shows how the optimal Hotelling rule of resource extraction needs to be modified when the future resource price is volatile. In particular, he finds that price volatility should bring forward the efficient resource extraction path, and Corollary 4 is a version of his result. We note that the higher the volatility, and the stronger the preference for the provision of public goods, $\gamma^{A}$ and $\gamma^{B}$, the more the socially efficient extraction path shall be tilted towards the present.

To see how we extend the previous literature on price volatility and the resource extraction path, we now move on to the next corollaries, which compare the extraction path in the political equilibrium with the socially optimal extraction path. The following corollary introduces a first main insight:

Corollary 5 Consider the case of symmetric preferences, i.e. $\gamma^{A}=\gamma^{B} \equiv \gamma$. Then when $R(e) R^{\prime \prime}(e)+R^{\prime}(e)^{2} \leq 0$ the extent of overextraction is higher the higher is price volatility, i.e. the higher is $\sigma^{2}$. 
Proof. When $\gamma^{A}=\gamma^{B}$, this immediately implies that $\Pi_{e}=0$ and that $\Pi=\frac{1}{2}$. Inserting this and $\gamma^{A}=\gamma^{B} \equiv \gamma,(29)$ and (30) can be written, respectively, as

$$
p_{1}+\overline{p_{2}} R^{\prime}\left(e^{*}\right)-\frac{1}{2} \overline{p_{2}} R^{\prime}\left(e^{*}\right)-\frac{1}{2} \gamma \sigma^{2} R\left(e^{*}\right) R^{\prime}\left(e^{*}\right)=0,
$$

and

$$
p_{1}+\overline{p_{2}} R^{\prime}\left(e^{f}\right)-\frac{1}{4} \gamma \sigma^{2} R\left(e^{f}\right) R^{\prime}\left(e^{f}\right)=0 .
$$

Thus the condition for resource extraction in the political equilibrium to increase more than the social optimal extraction reduces to

$$
-2 R\left(e^{*}\right) R^{\prime}\left(e^{*}\right)>-R\left(e^{f}\right) R^{\prime}\left(e^{f}\right)
$$

Thus this will always hold provided $e^{*}$ is not too high compared to $e^{f}$. Moreover, if $R(e) R^{\prime \prime}(e)+R^{\prime}(e)^{2} \leq 0$ this always hold since in this case we have that $\left|R\left(e^{*}\right) R^{\prime}\left(e^{*}\right)\right| \geq$ $\left|R\left(e^{f}\right) R^{\prime}\left(e^{f}\right)\right|$.

To see the main intuition behind this corollary, note that a social planner will smooth future price volatility between the two groups of voters since they both will have positive provision of public goods. In a political equilibrium, by contrast, only one of the groups will receive public goods, and thus price volatility generates higher volatility in provision for the group that happens to be in power. As a consequence, since volatility is not smoothed across groups, future volatility is more costly. Thus, when volatility increases, resource extraction is tilted towards the present by more than what is socially optimal. This effect is captured by the term 2 on the left hand side of (36).

There are also two additional effects. One the one hand, as captured by the terms $R\left(e^{*}\right)<$ $R\left(e^{f}\right)$ in (36), the fact that resource extraction is higher in the political equilibrium than in the social optimum means that in political equilibrium less resources are left for the future. Thus in political equilibrium a lower resource stock is exposed to volatility, and therefore increased volatility is less costly than in social equilibrium. As a consequence, higher volatility increases extraction less today than in the social efficient extraction path. On the other hand, there is an effect captured by the terms $-R^{\prime}\left(e^{*}\right)>-R^{\prime}\left(e^{f}\right)$. In political equilibrium the marginal amount of resources gained in the future if extraction today is reduced is higher than in social equilibrium. When volatility increases, the marginal value of future resources thus decreases most in the political equilibrium, pushing down extraction today by more in the political equilibrium than in the social equilibrium. In the special case where $R(e) R^{\prime \prime}(e)+R^{\prime}(e)^{2}=0$, these two latter effects cancel, and only the first remains, which explains why in this case higher resource price volatility always increases overextraction.

Turning finally to the case of asymmetric preferences, i.e. $\gamma^{A} \neq \gamma^{B}$, we have: 
Corollary 6 Consider the case of asymmetric preferences, and let $\gamma^{A}>\gamma^{B}$. Then from (29) the term $\Pi_{e}\left(V_{\text {power }}\right)$ becomes positive.

(i) This increases overextraction in political equilibrium even more.

(i) Provided $\sigma^{2}$ is not too high initially, this increase in overextraction increases in $\sigma^{2}$.

Proof. Part (i) follows directly as the left hand side of (29) has now become higher.

To see part (ii), note that the derivative of the term $\Pi_{e}\left(V_{\text {power }}\right)$ with respect to $\sigma^{2}$ is given by

$$
\Pi_{e \sigma^{2}}\left(V_{\text {power }}\right)+\Pi_{e} \gamma^{A} \frac{1}{2} R\left(e^{*}\right)^{2},
$$

which by inserting for $\Pi_{e \sigma^{2}}$ and $\Pi_{e}$ exceeds zero if

$$
\overline{p_{2}} R\left(e^{*}\right)+\frac{1}{2 \gamma^{A}}-\bar{G}-\gamma^{A} \sigma^{2} R\left(e^{*}\right)^{2}+\frac{\gamma^{A}}{2}(\bar{G})^{2}>0,
$$

which is always satisfied provided $\sigma^{2}$ is not too high.

The intuition for part (i) is that when the group that values public goods the most has power, then greater resource extraction in the present increases the probability of holding future political power, since it implies a lower volatility cost for the voters which is stronger for group $A$ voters than for group $B$ voters. This increases overextraction even more as compared to the symmetric case.

The intuition for part (ii) is that, on the one hand, a higher volatility decreases the value for the politician of future political power. Since it becomes less important for him to win, his incentive to extract more today to secure future political power has become weaker. On the other hand, however, higher volatility also means that voters have become more responsive: higher extraction today increases the probability of reelection by more when volatility is high. This pulls in the direction of higher extraction, and given that the rents of power are sufficiently large, which they are if $\sigma^{2}$ is sufficiently low, this effect always dominates. In that case, the increase in overextraction is increasing in $\sigma^{2}$, as stated in part (ii) of the corollary.

Thus, even in the absence of political patronage a political economy model of price volatility brings novel and interesting effects for resource extraction. Further interesting implications follow when we also allow resource extraction to interact with political patronage, a topic to which we now turn.

\subsection{Extension: resource extraction with patronage employment}

In this extension, to focus on the most interesting interactions between resource extraction and patronage employment, we investigate the case of asymmetric preferences, and thus again assume that $\gamma^{A}>\gamma^{B}$.

With patronage $L_{1}^{A}>0$ the corresponding first order conditions for $L_{1}^{A}$ and $e$ are:

$$
-(1+\Pi) W+\Pi_{L}^{\prime}\left(V_{\text {power }}\right)=0,
$$




$$
p_{1}+\Pi_{e}\left(V_{\text {power }}\right)+\Pi\left(\overline{p_{2}}-\gamma^{A} \sigma^{2} R(e)\right) R^{\prime}(e)=0,
$$

with

$$
V_{\text {power }}=\overline{p_{2}} R(e)-W L_{1}^{A}+\frac{1}{2 \gamma^{A}}-\bar{G}-\gamma^{A} \frac{\sigma^{2}}{2} R(e)^{2}+\frac{\gamma^{A}}{2}(\bar{G})^{2} .
$$

Equation (37) defines a political patronage curve $L_{1}^{A}(e)$. As shown in the Appendix, the effect of the resource extraction rate $e$ on $L_{P}$ involves two effects. First, it increases the probability of reelection and therefore increases the expected resource cost of political patronage. Second, it reduces the net value of staying in power for the incumbent. For both reasons the incentives of the incumbent to offer public jobs are reduced, and political patronage is consequently a negative function of the extraction rate. This relationship is depicted as the solid curve $L_{1}^{A}(e)$ in Figure 2.

Similarly equation (38) defines the extraction rate curve $e\left(L_{1}^{A}\right)$. An increase in $L_{1}^{A}$ has also two effects. First, a higher value of $L_{1}^{A}$ reduces the incumbent's value to stay in power (as the wage bill to be paid on the public budget is increased). This in turn weakens the incentive to push resource extraction up to increase the election probability, and therefore reduces $e$. Second, more political patronage increases the time horizon of the incumbent and therefore makes him more likely to keep resources for the next period. Hence, the effect of political patronage on the extraction rate is negative. This relationship is depicted as the solid curve $e\left(L_{1}^{A}\right)$ in Figure 2 .

The equilibrium policies can be represented as before in the space $\left(e, L_{1}^{A}\right)$ in Figure 2 , at point $E$ where the two solid curves intersect.

\section{Figure 2 about here.}

\section{Price volatility and the resource curse}

The effect of price volatility on the equilibrium values of $e$ and $L_{1}^{A}$ is obtained through differentiation of (38) and (37). In the Appendix we show that (for given extraction) volatility increases patronage when the public wage gap is not too large, and the $L_{1}^{A}(e)$-curve then shifts to the right. Again the effect of volatility on extraction (for given patronage) makes the $e\left(L_{1}^{A}\right)$-curve shifts upwards provided the volatility is not too high.

The induced effect of $\sigma^{2}$ on the equilibrium policies are described by the dotted curves in Figure 2. Inspection shows immediately that at least one of the variables increases, and quite possibly (as drawn in the figure) they both increase. In that case extraction and patronage employment both increase with higher price volatility.

It is straight forward to verify that in the case where both extraction and patronage employment increase, total income decreases both as a result of a worse extraction path and as a result of increased patronage employment. Thus in this case we have a resource curse for both 
reasons. In case one of the variables decrease, the total effect on income is uncertain (see the Appendix).

\section{Concluding remarks}

In this paper we have developed a model of the political consequences of public income volatility which to our knowledge has not previously been researched. As is standard, political incentives create inefficient public policies in our model, but we also show that making income uncertain creates specific new effects. Future volatility reduces the benefit of being in power, making policy more efficient. Yet at the same time it also reduces the re-election probability of an incumbent and since some of the policy inefficiencies are concentrated in the future, this makes inefficient policy less costly. We show how this model can help think about the connection between volatility and economic growth and in the case where volatility comes from volatile natural resource prices, a characteristic of many developing countries, we show that volatility in itself is a source of inefficient resource extraction. These results are in addition and complementary to those of van der Ploeg (2010) who showed how uncertainly about natural resource wealth increases the socially efficient extraction rate. 


\section{References}

Acemoglu, Daron, James A. Robinson and Thierry Verdier (2004) "Kleptocracy and Divide-and-Rule: A Model of Personal Rule," Journal of the European Economic Association, 2, 162-192.

Acemoglu, Daron and Fabrizio Zilibotti (1997) "Was Prometheus Unbound by Chance? Risk, Diversification, and Growth," Journal of Political Economy, 105(4), 709-751.

Aghion, Philippe and Patrick Bolton (1990) "Government Domestic Debt and the Risk of Default: A Political-Economic Model of the Strategic Role of Debt," in Rudiger Dornbusch and Mario Draghi eds. Public Debt Management: Theory and History, Cambridge: MIT Press.

Aghion, Philippe and Abhijit V. Banerjee (2005) Volatility and Growth, New York: Oxford University Press.

Aghion, Philippe, George-Marios Angeletos, Abhijit V. Banerjee and Kalina Manova (2010) "Volatility and Growth: Credit Constraints and the Composition of Investment," Journal of Monetary Economics, 57(3), 246-265.

Alesina, Alberto and Guido Tabellini (1990a) "A Positive Theory of Fiscal Deficits and Government Debt," Review of Economic Studies, 57, 403-14.

Alesina, Alberto and Guido Tabellini (1990b) "Voting on the Budget Deficit," American Economic Review, 80, 37-49.

Biais, Bruno and Enrico Perotti (2002) "Machiavellian Privatization," American Economic Review, 92(1), 240-258.

Besley, Timothy and Stephen Coate (1998) "Sources of Inefficiency in a Representative Democracy: A Dynamic Analysis," American Economic Review, 88(1), 139-156.

Bleaney, Michael and Håvard Halland (2010) "The Resource Curse and Fiscal Policy Volatility," CREDIT Research paper 09/09, University of Nottingham.

Frankel, Jeffrey A. (2012) "The Natural Resource Curse: A Survey," in Brenda Shaffer and Taleh Ziyadov, eds. Beyond the Resource Curse, Philadelphia: University of Pennsylvania Press.

Koren, Miklós and Silvana Tenreyro (2007) "Volatility and Development," Quarterly Journal of Economics, 122(1), 243-287.

Leblanc, William, James M. Snyder and Micky Tripathi (2000) "Majority-rule Bargaining and the Under Provision of Public Investment Goods," Journal of Public Economics, $75,21-47$.

Leong, Weishu and Kamiar Mohaddes (2011) "Institutions and the Volatility Curse," CWPE 1145, University of Cambridge.

Lindbeck, Assar and Jörgen W. Weibull (1987) "Balanced-budget Redistribution as the Outcome of Political Competition," Public Choice, 52, 273-297. 
Loayza, Norman V., Romain Rancière, Luis Servén, and Jaume Ventura (2007) "Macroeconomic volatility and welfare in developing countries: an introduction," World Bank Economic Review, 21, 343-57.

Moene, Karl, Halvor Mehlum and Ragnar Torvik (2006) "Institutions and the Resource Curse," Economic Journal, 116, 1-20.

Persson, Torsten and Gudio Tabellini (2000) Political Economics, Cambridge: MIT Press.

Ramey, Gary and Valerie A. Ramey (1995) "Cross-country evidence on the link between volatility and growth," American Economic Review, 85, 1138-1151.

Robinson, James A. and Ragnar Torvik (2005) "White Elephants," Journal of Public Economics, 89, 197-210.

Robinson, James A., Ragnar Torvik and Thierry Verdier (2006) "Political Foundations of the Resource Curse," Journal of Development Economics, 79, 447-468.

Robinson, James A., Ragnar Torvik and Thierry Verdier (2014) "Political Foundations of the Resource Curse: A Simplification and a Comment," Journal of Development Economics, 106, 194-198.

Robinson, James A. and Thierry Verdier (2013) "The Political Economy of Clientelism," Scandinavian Journal of Economics, 115 (2): 260-291.

van der Ploeg, Frederick and Steven Poelhekke (2009) "Volatility and the Natural Resource Curse," Oxford Economic Papers, 61, 727-760.

van der Ploeg, Frederick and Steven Poelhekke (2010) "The pungent smell of "red herrings": subsoil assets, rents, volatility, and the resource curse," Journal of Environmental Economics and Management, 60, 44-55.

van der Ploeg, Frederick (2010) "Aggressive Oil Extraction and Precautionary Saving: Coping with Volatility," Journal of Public Economics, 94, 421-433.

van der Ploeg, Frederick (2011) "Natural resources: curse or blessing?, Journal of Economic Literature, 49, 2, 366-420. 


\section{Appendix}

In this Appendix we provide derivations and analysis referred to in the different sections of the main paper.

\subsection{Appendix to Section 2.6}

- The curves $L_{1}^{A}(I)$ and $I\left(L_{1}^{A}\right)$ :

The $L_{1}^{A}(I)$-curve is defined by (23), and differentiation of (23) gives:

$$
\begin{aligned}
\frac{\partial L_{1}^{A}(I)}{\partial I} & =\frac{-\Pi_{I}\left(W+\tau H_{2}\right)-\Pi \tau \delta+\Pi_{L I}\left[V_{\text {power }}\right]+\Pi_{L}^{\prime} \tau \delta\left(1-L_{1}^{A}\right)}{2 \Pi_{L}\left[W+\tau H_{2}\right]} \\
& =\frac{h(1-\tau) \delta\left(W+\tau H_{2}\right) L_{1}^{A}-\Pi \tau \delta-h \delta(1-\tau)\left[V_{\text {power }}\right]+h\left[W-H_{2}(1-\tau)\right] \tau \delta\left(1-L_{1}^{A}\right)}{2 \Pi_{L}\left[W+\tau H_{2}\right]} .
\end{aligned}
$$

Similarly the $I\left(L_{1}^{A}\right)$-curve is given by (24), and differentiation of this provides:

$$
\frac{\partial I\left(L_{1}^{A}\right)}{\partial L_{1}^{A}}=\frac{h(1-\tau) \delta\left(W+\tau H_{2}\right) L_{1}^{A}-\Pi \tau \delta-h \delta(1-\tau)\left[V_{\text {power }}\right]+h\left[W-H_{2}(1-\tau)\right] \tau \delta\left(1-L_{1}^{A}\right)}{-2 \Pi_{I}^{\prime} \tau \delta\left(1-L_{1}^{A}\right)} .
$$

The denominator in both of these expressions is positive (which is also a requirement for the second order conditions of the maximization problem to be fulfilled), and thus the sign of the expressions is determined by the numerator (which naturally is the same in both expressions since it is the cross derivative of the maximand). The numerator in the expressions is negative when

$$
V_{\text {power }}>\left(W+\tau H_{2}\right) L_{1}^{A}-\frac{\Pi \tau}{h(1-\tau)}+\left(\frac{W}{1-\tau}-H\right) \tau\left(1-L_{1}^{A}\right) .
$$

Since we are interested in resource abundant countries where the value to remain in power is high, we assume this to be fulfilled (for instance due to $\overline{p_{2}} Z$ being sufficiently large). The slope of the curves is then negative (and the second order condition requires the $L_{1}^{A}(I)$-curve to be steeper then the $I\left(L_{1}^{A}\right)$-curve as depicted in Figure 1).

\section{- Impact of volatility on the $L_{1}^{A}(I)$-curve:}

Differentiation of (23) with respect to $L_{1}^{A}$ and $\sigma^{2}$ (for given $I=\bar{I}$ ) shows that the horizontal shift in the $L_{1}^{A}(I)$-curve is given by

$$
\frac{\partial L_{1}^{A}(\bar{I})}{\partial \sigma^{2}}=\frac{-\Pi_{\sigma^{2}}\left(W+\tau H_{2}\right)-\Pi_{L}^{\prime} \frac{\gamma^{A}}{2}}{2 \Pi_{L}\left[W+\tau H_{2}\right]},
$$

where the denominator is positive. Inserting in the numerator for $\Pi_{\sigma^{2}}$ and $\Pi_{L}^{\prime}$, the sign of the numerator and the horizontal shift is positive when

$$
h\left(\gamma^{A}-\gamma^{B}\right) \frac{1}{4}\left(W+\tau H_{2}\right)-h\left(W-H_{2}(1-\tau)\right) \frac{\gamma^{A}}{2}>0
$$


which reduces to

$$
\frac{2 \gamma^{A}}{\gamma^{A}+\gamma^{B}}>\frac{W}{H_{2}}+\tau
$$

Hence, for a given level of investment, volatility increases patronage (all else controlled for) when the heterogeneity in preferences is sufficiently high, and then the $L_{1}^{A}(I)$-curve shifts to the right.

\section{- Impact of volatility on the $I\left(L_{1}^{A}\right)$-curve:}

Similarly differentiation of (24) with respect to $I$ and $\sigma^{2}$ (for given $L_{1}^{A}=\overline{L_{1}^{A}}$ ) shows that the vertical shift in the $I\left(L_{1}^{A}\right)$-curve as a result of higher volatility is given by

$$
\frac{\partial I\left(\overline{L_{1}^{A}}\right)}{\partial \sigma^{2}}=\frac{\Pi_{\sigma^{2}} \tau \delta\left(1-L_{1}^{A}\right)-\Pi_{I}^{\prime} \frac{\gamma^{A}}{2}}{-2 \Pi_{I}^{\prime} \tau \delta\left(1-L_{1}^{A}\right)},
$$

where the denominator is positive, and the sign of the vertical shift is negative when the numerator is negative, which after substituting for $\Pi_{\sigma^{2}}$ and $\Pi_{I}^{\prime}$ holds when

$$
-h\left(\gamma^{A}-\gamma^{B}\right) \frac{1}{4} \tau \delta\left(1-L_{1}^{A}\right)+h \delta(1-\tau) L_{1}^{A} \frac{\gamma^{A}}{2}<0
$$

which reduces to

$$
\frac{\tau\left(1-\frac{\gamma^{B}}{\gamma^{A}}\right)}{2+\tau\left(1+\frac{\gamma^{B}}{\gamma^{A}}\right)}>L_{1}^{A}
$$

The left hand side is decreasing in $\frac{\gamma^{B}}{\gamma^{A}}$ (as $\tau<1$ ), and in the simple case where only group $A$ voters care for public goods the condition simply reduces to $\tau>L_{1}^{A}$. Hence public investment declines with $\sigma^{2}$ when the size of public employment is not too large compared to fiscal capacity $\tau$.

\subsection{Appendix to Section 3.3}

- The curves $L_{1}^{A}(e)$ and $e\left(L_{1}^{A}\right)$ :

The $L_{1}^{A}(e)$-curve is defined by (37) and differentiation provides:

$$
\frac{\partial L_{1}^{A}(e)}{\partial e}=\frac{-\Pi_{e} W+\Pi_{L}^{\prime}\left(\overline{p_{2}}-\gamma^{A} \sigma^{2} R(e)\right) R^{\prime}(e)}{2 \Pi_{L}^{\prime} W}<0 .
$$

Similarly the $e\left(L_{1}^{A}\right)$-curve is defined by (38) and differentiation provides:

$$
\frac{\partial e\left(L_{1}^{A}\right)}{\partial L_{1}^{A}}=\frac{-\Pi_{e}^{\prime} W+\Pi_{L}^{\prime}\left(\overline{p_{2}}-\gamma^{A} \sigma^{2} R(e)\right) R^{\prime}(e)}{-Q}<0,
$$

where the sign follows from $\Pi_{e}^{\prime}>0$ and $\Pi_{L}^{\prime}>0$. We assume that the second order conditions are fulfilled, which implies that the $L_{1}^{A}(e)$-curve is steeper than the $e\left(L_{1}^{A}\right)$-curve as depicted in Figure 2. 
- Impact of volatility on the $L_{1}^{A}(e)$-curve:

Differentiation of (37) with respect to $L_{1}^{A}$ and $\sigma^{2}$ (for given $e=\bar{e}$ ) shows that the horizontal shift in the $L_{1}^{A}(e)$-curve is given by

$$
\frac{\partial L_{1}^{A}(\bar{e})}{\partial \sigma^{2}}=\frac{-\Pi_{\sigma^{2}} W-\Pi_{L}^{\prime} \frac{\gamma^{A}}{2} R(e)^{2}}{2 \Pi_{L} W}
$$

where the denominator is positive, and the sign of the horizontal shift depends on the sign of

$$
\underbrace{-\Pi_{\sigma^{2}} W}_{+} \underbrace{-\Pi_{L}^{\prime} \frac{\gamma}{2 \bar{q}^{2}} R(e)^{2}}_{-},
$$

which after substituting for $\Pi_{\sigma^{2}}$ and $\Pi_{L}^{\prime}$ is positive when

$$
h\left(\gamma^{A}-\gamma^{B}\right) \frac{1}{4} R(e)^{2} W-h(W-H) \frac{\gamma^{A}}{2} R(e)^{2}>0,
$$

which reduces to

$$
\frac{2 \gamma^{A}}{\gamma^{A}+\gamma^{B}}>\frac{W}{H}
$$

Hence, for a given level of extraction, volatility increases patronage (all else controlled for) when policy preferences are sufficiently heterogenous between groups, and/or if public wages are not too high compared to private sector productivity, and then the $L_{1}^{A}(e)$-curve shifts to the right.

\section{- Impact of volatility on the $e\left(L_{1}^{A}\right)$-curve:}

Similarly differentiation of (38) with respect to $e$ and $\sigma^{2}$ (for given $L_{1}^{A}=\overline{L_{1}^{A}}$ ) shows that a sufficient condition for the $e\left(L_{1}^{A}\right)$-curve to shift upwards with higher volatility is that price volatility is not too strong.

Total income over the two periods is again given by

$$
Y_{1}+Y_{2}=2 H+p_{1} e+\overline{p_{2}} R(e)-\left(1+\Pi\left(L_{1}^{A}\right)\right) L_{1}^{A}
$$

and the derivative for $\sigma^{2}$ gives

$$
\frac{\partial\left(Y_{1}+Y_{2}\right)}{\partial \sigma^{2}}=\left[p_{1}+\overline{p_{2}} R^{\prime}(e)\right] \frac{\partial e}{\partial \sigma^{2}}-\left[1+\Pi+\Pi_{L}^{\prime} L_{1}^{A}\right] \frac{\partial L_{1}^{A}}{\partial \sigma^{2}} .
$$

As there is overextraction of the incumbent $\left[p_{1}+\overline{p_{2}} R^{\prime}(e)\right]<0$, and obviously when $e$ and $L_{1}^{A}$ increase the effect on income is negative. If one of the variables decreases, then in general the effect cannot be signed. 
Figure 1

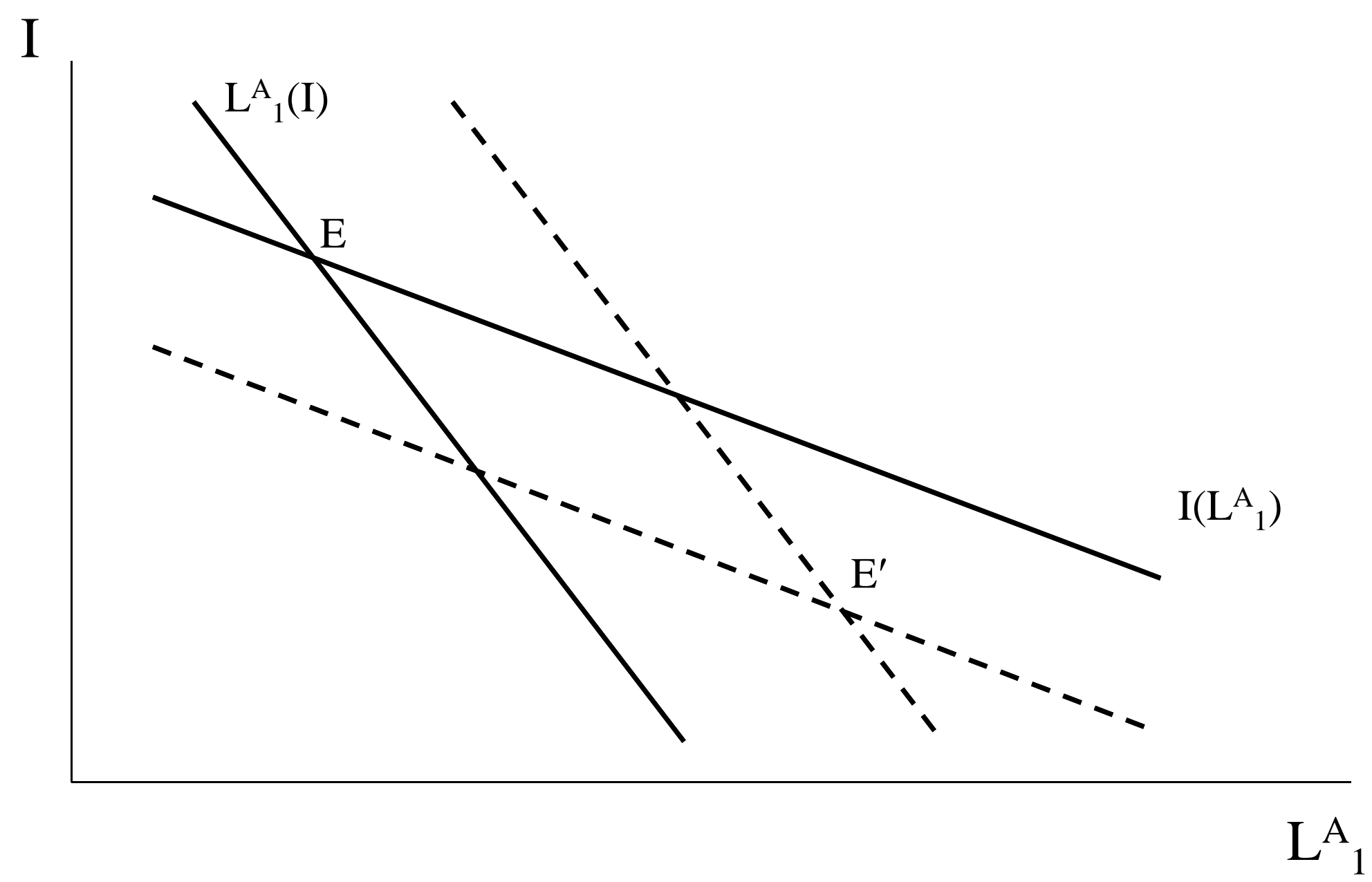


Figure 2

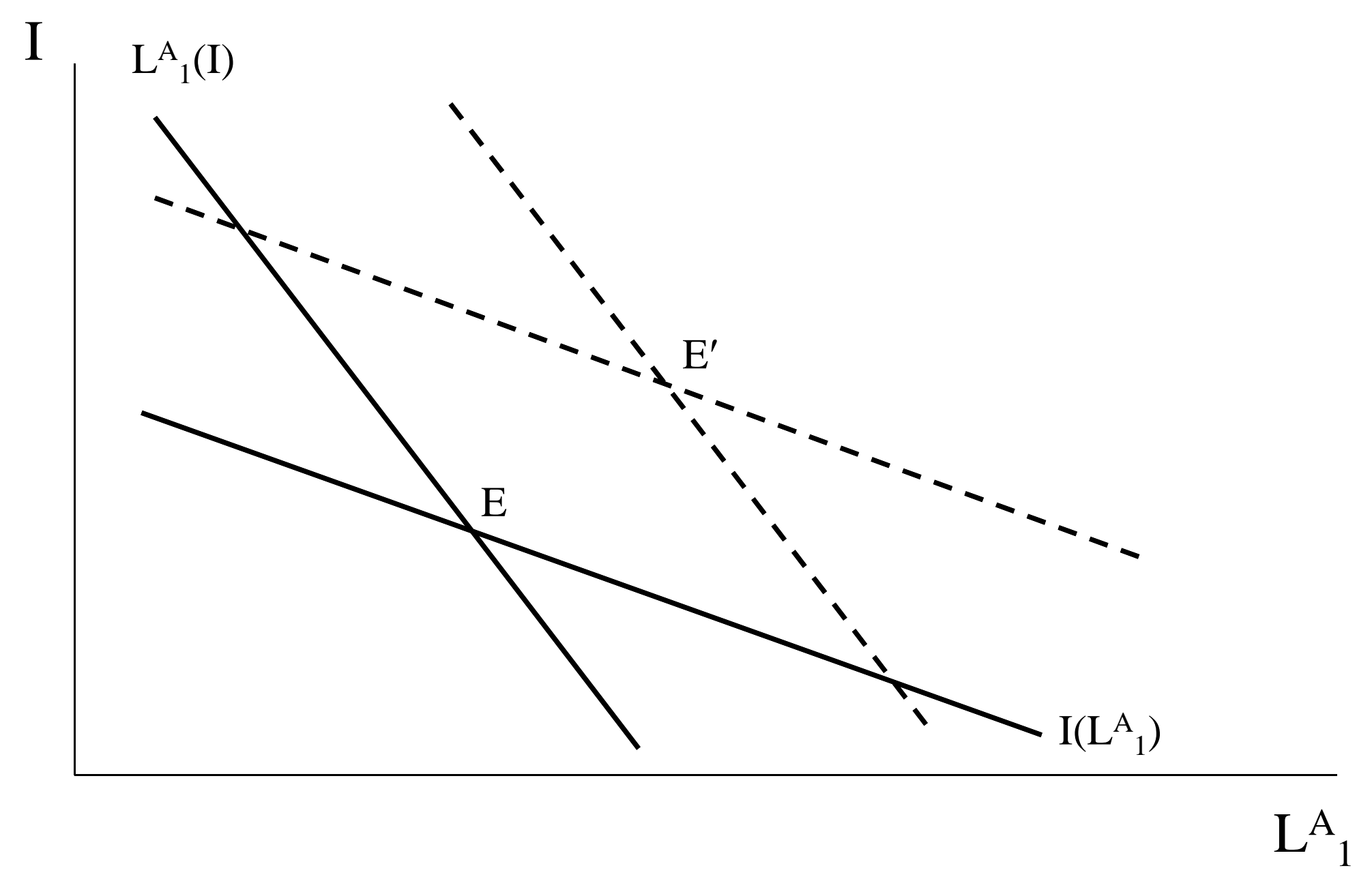

